[Technical Paper]

\title{
Effects of Internal Stress of Electroless Nickel Plating on Solder Joining Strength
}

\author{
Katsumi Miyama, Kanou Yoshida, Shigeru Saitou, and Toshiyuki Takashima \\ Dept. of Mechanical Engineering, Faculty of Engineering, Hokkaido University of Science, 7-15-4-1 Maeda, Teine, Sapporo, Hokkaido 006-8585, Japan
}

(Received April 5, 2015; accepted July 21, 2015)

\begin{abstract}
Nickel/gold electroless plating is commonly used for surface finishing of printed wiring board due to its environmental stability and good solder wettability. However, since the gold deposition of electroless gold plating is a substitution reaction, local corrosion of nickel surfaces sometimes occurs which decreases the joining reliability of solders or wire bonding.

In this study, we focused on the internal stress of the nickel-plating layer. Gold electroless plating was performed on nickel plating with different internal stress levels, and the local corrosion behavior and shear strength of solder balls were investigated. Our results clearly show that the tensile strength of the nickel layer increases the occurrence of local corrosion and accordingly results in the deterioration of the solder joining strength.
\end{abstract}

Keywords: Electroless Plating, PCBs, Internal Stress, Solder Ball Shear Test, Local Corrosion, pH Control

\section{Introduction}

Electroless nickel/gold plating is widely used for surface finish of PCBs. Particularly substitutional gold plating has been applied not only to soldering pads but also exposed termination such as keypads due to its excellent oxidation resistance and reasonable manufacturing cost. Substitutional reaction of $\mathrm{Au}$ and $\mathrm{Ni}$ behavior is very uniform, but infrequently the reaction occurs locally for some reasons. That means local dissolution of $\mathrm{Ni}$ results in a defect at the $\mathrm{Ni} / \mathrm{Au}$ interface. This phenomenon is well known as so-called "Local corrosion" or "Black pad". These defects often cause serious bonding failures of mounted devices.[1, 2] A cause of local corrosion is basically incorrect control of chemical composition of plating solution. However, actual mechanism seems to be very complicate interaction with several factors, such as surface finish of copper surface, mechanical properties of substrate and plated layer, etc. In this study, we focused on internal stress of electroless nickel plated layer, and considered the effect of internal stress on local corrosion behavior and solder joining strength.

\section{Experimental Procedure}

\subsection{Chemicals and equipment}

Commercially available plating chemicals were used in this study. Nickel plating chemical was mid-phosphorous type with hypophosphite as reduction agent. For gold plating, substitution reaction type chemical of mild acidity with gold cyanide was used. Prior to nickel plating, substrates were degreased in acetone with ultrasonic cleaning and rinsed in distilled water. Subsequently the surfaces of substrates were chemically etched approximately $1 \mu \mathrm{m}$ with sulfuric acid/hydrogen peroxide solution to remove oxidized surface and contaminations. After that, they were immediately catalytic activated with sulfuric based palladium solution and followed by the nickel plating and the gold plating. Since it has been known that internal stress of electroless nickel plating is affected by $\mathrm{pH}$ of plating solution,[3] nickel plating was performed in several different $\mathrm{pH}$ at a range of 4.0 to 6.0. That was adjusted with aqueous ammonia or 10 vol\% sulfuric acid solution. The nickel plating equipment is illustrated in Fig. 1. The plating solution was electrically heated and agitated with air bubbling. Gold plating was performed with a glass beaker by temperature controlling with mantle heater at $85^{\circ} \mathrm{C}$ for 
$15 \mathrm{~min}$.

FE-SEM (JEOL JSM-7001F) and FIB-SEM (JEOL JEB$4600 \mathrm{~F} / \mathrm{HKD})$ were used for observation of cross-section, and AES (Auger Electron Spectroscopy; JEOL JAMP9500F) was used for element analyses of plating surfaces. Metallic phase of plated layer was determined by XRD (Rigaku SmartLab).

\subsection{Substrate material}

Observation samples for cross section and surface morphology were $20 \mathrm{~mm}$ width, $25 \mathrm{~mm}$ length and $0.5 \mathrm{~mm}$ thickness of FR-4 grade double sided copper laminate including copper foil of $0.035 \mathrm{~mm}$ thickness (Panasonic R-1566). For observation of surface morphology of nickel, gold plating layer was dissolved with sodium cyanide solution (P-8000N; Sasaki Chemical Co., Ltd.).

\subsection{Measurement of internal stress}

Internal stress of nickel plating layer was measured by "Test Strip Method" as depicted in Fig. 2. The measurement was performed with $0.10 \mathrm{~mm}$ thick C-1940 (Cu-2.4Zn$1.0 \mathrm{Fe}$; mass\%) strip which has two legs, each with one side coated to prevent plating. Since the bare sides of the strip

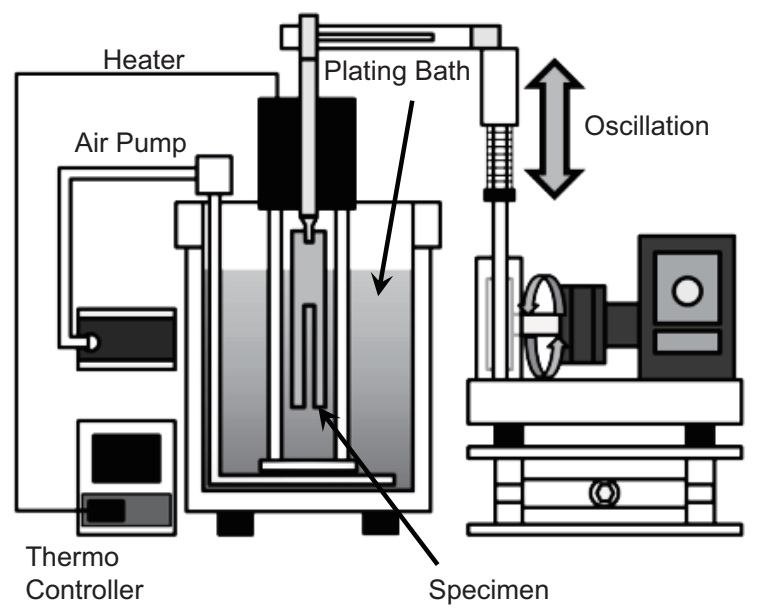

Fig. 1 Nickel plating equipment. legs face opposite directions, a stressed deposit results in a net spread with each of the legs bending either toward (compressive deposit) or away (tensile) from its exposed surface. $[4,5]$

\subsection{Solder ball shear test}

In order to evaluate effects of internal stress of plated layer on solder joining strengths, solder ball shear strengths were measured. Substrates for the ball shear test were fabricated with FR-4 grade material as with the morphology observation specimens. Dimensions of them were $20 \mathrm{~mm}$ width, $25 \mathrm{~mm}$ length and $0.4 \mathrm{~mm}$ thickness. After screen printing of solder mask ink on the whole surface of the copper foil of the substrate and thermally precuring, solder mask openings of $0.65 \mathrm{~mm}$ diameter were formed by photo lithography. After that, nickel/gold electroless plating was performed in different $\mathrm{pH}$ of nickel plating bath, 4.0, 5.0 and 6.0. Next, solder bumps were formed with solder balls of $0.76 \mathrm{~mm}$ diameter (Senju M705, Sn-3.5Ag-0.5Cu; mass\%) at the solder mask openings of the substrates by reflow soldering at $250^{\circ} \mathrm{C}$ in the ambient air. The substrate temperature was monitored with a thermocouple. After removing soldering flux in the solvent, the ball shear test was carried out using a bondtester (Dage Series4000) under the conditions of 7.00 $\mathrm{mm} / \mathrm{s}$ in shear speed and $20 \mu \mathrm{m}$ in test height. After the ball shear tests, the fracture surfaces and the cross sections were observed using SEM.

\section{Results and Discussion}

\subsection{Internal stress of nickel plating}

The test strips were nickel plated under several conditions as shown in Table 1 . The legs of the test strips deform on a constant curvature radius depending on generated internal stress so that the internal stress can be determined from Stoney's model.[6] The internal stress $\sigma$

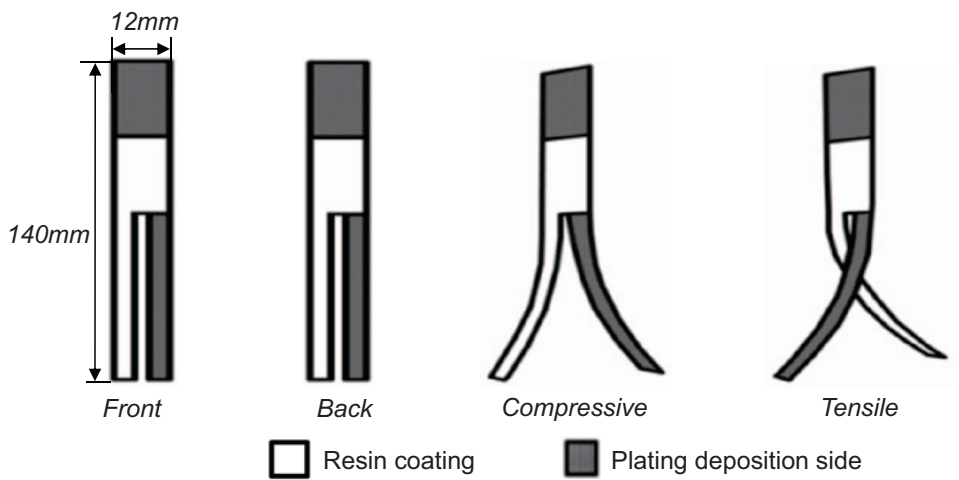

a. Test strip

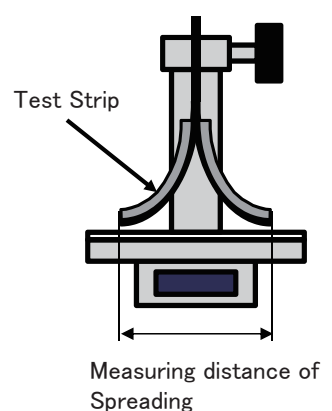

b. Measurement

Fig. 2 Measurement of internal stress. 
Table 1 Plating conditions.

\begin{tabular}{l|l|l}
\hline \multirow{4}{*}{$\begin{array}{l}\text { Nickel } \\
\text { Plating }\end{array}$} & Ni concentration & $6.0( \pm 0.3) \mathrm{g} / \mathrm{L}$ \\
\cline { 2 - 3 } & $\mathrm{pH}$ & $4.0,4.5,5.0,5.5,6.0$ \\
\cline { 2 - 3 } & Bath Temp. $\left({ }^{\circ} \mathrm{C}\right)$ & $70,75,80,85,90$ \\
\hline \multirow{3}{*}{$\begin{array}{l}\text { Gold } \\
\text { Plating }\end{array}$} & Au concentration & $2.0 \mathrm{~g} / \mathrm{L}$ \\
\cline { 2 - 3 } & $\mathrm{pH}$ & 4.8 \\
\cline { 2 - 3 } & Bath Temp. $\left({ }^{\circ} \mathrm{C}\right)$ & 86 \\
\hline
\end{tabular}

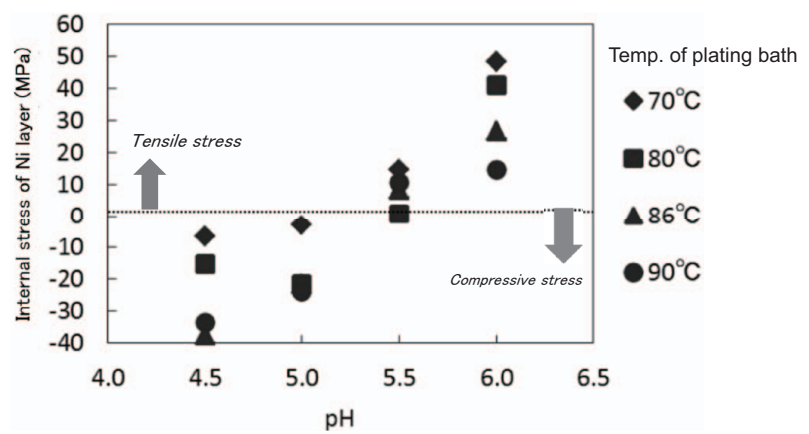

Fig. 3 Internal stress of nickel layer measured by test strip method.

can be calculated by following equation; [7]

$$
\sigma=E T_{s}^{2} / 6 R T_{F}
$$

where $E$ is Young's modulus of the substrate material (the test strip), $T_{S}$ is the thickness of the substrate, $R$ is the curvature radius of the strip after plating, and $T_{F}$ is the thickness of plating. Calculated internal stresses are depicted in Fig. 3. It was confirmed that compressive internal stress in lower $\mathrm{pH}$ varied to tension as raising $\mathrm{pH}$. Since the temperature of plating bath did not have significant influences on the internal stress, the remaining experiments were carried out at $85^{\circ} \mathrm{C}$.

Ni-P alloy of mid-P type plating deposits as amorphous phase basically, but a possibility of deposition of crystalline phase is known in case of high pH. If there would be a difference in metallic phase among plated specimens, it might affect to local corrosion behavior. In order to determine metallic phase of nickel plating layer, XRD analysis was carried out. The results are shown in Fig. 4. The Ni diffraction peaks presented broad spectrum at the angle of 2 -theta corresponding to (111) plane diffraction. And no further peak was detected except $\mathrm{Cu}$ peaks from the substrate. These broad peaks are characteristically for amorphous phase. This result indicated that metallic phases of nickel plated layer were amorphous in all specimens even in case of $\mathrm{pH}$ 6.0. In addition, $\mathrm{P}$ content in plated Ni was analyzed using EDS because it is known that it varies depending on bath $\mathrm{pH}$. The analysis indicated 9.6 mass\% $\mathrm{P}$ in $\mathrm{pH} 4.0,8.2 \mathrm{mass} \%$ in $\mathrm{pH} 5.0$, and 7.2 mass\% in $\mathrm{pH}$ 6.0.

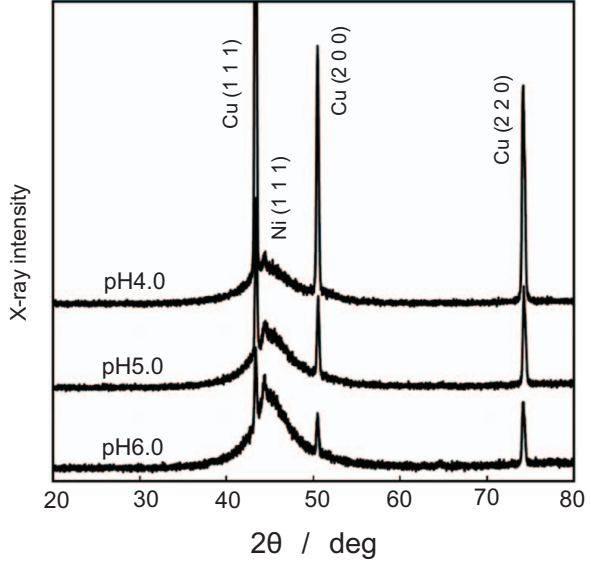

Fig. 4 XRD pattern of nickel layer in different $\mathrm{pH}$.

\subsection{Behavior of local corrosions}

Local corrosion behavior was compared in different internal stress level by varying $\mathrm{pH}$ of nickel plating bath. The substrate specimens which were described in section 2.2 were nickel plated in different $\mathrm{pH}, 4.0,5.0$, and 6.0 at $85^{\circ} \mathrm{C}$. Gold plating was performed under the same condition, at $85^{\circ} \mathrm{C}$ for $15 \mathrm{~min}$. After gold plating, the specimens were cross-sectioned by FIB (Focused Ion Beam). The cross-sectioned SEM images are shown in Fig. 5. Specimen (a) has compression internal stress, (b) has neutral small stress, and (c) has tensional one. There were some defects at nickel surfaces which seemed to be local corrosion in all specimens as indicated by broken lines, however, larger local corrosions could be seen in specimen (c) which has tensile internal stress than the other two specimens. Next, SEM images of the nickel surface after etching gold plating layer out were binarized by image processing and area ratio of local corrosions were calculated in order to quantify local corrosion behavior. Calculated results are shown in Fig. 6. An area ratio of local corrosion of the specimen plated at $\mathrm{pH} 4.0$ was $0.7 \%$ in average. It increased as raising $\mathrm{pH}$ linearly and it became $2.1 \%$ in case of $\mathrm{pH}$ 6.0. These results indicate that tensile internal stress may be a cause of local corrosion. Its mechanism would be similar to SCC (Stress Corrosion Cracking) which is serious corrosion phenomena occurring in austenitic stainless steel. It is well-known that tensile stress which is lower than yield stress of the material accelerates corrosion reaction. Since surface morphology of plated nickel is an aggregate of nodules, it is rough. It was presumed that tensile stress which concentrated at nodule boundaries accelerated local corrosion.

Beyond, the surfaces of nickel were analyzed by AES (Auger Electron Spectroscopy) in order to determine existence or non-existence of impurities or elemental segrega- 


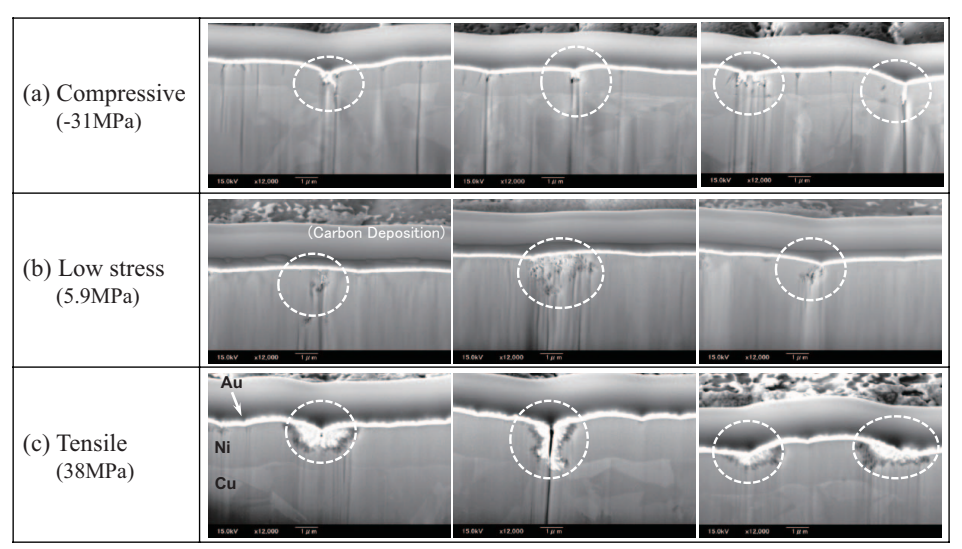

Fig. 5 FIB cross sections of local corrosions.

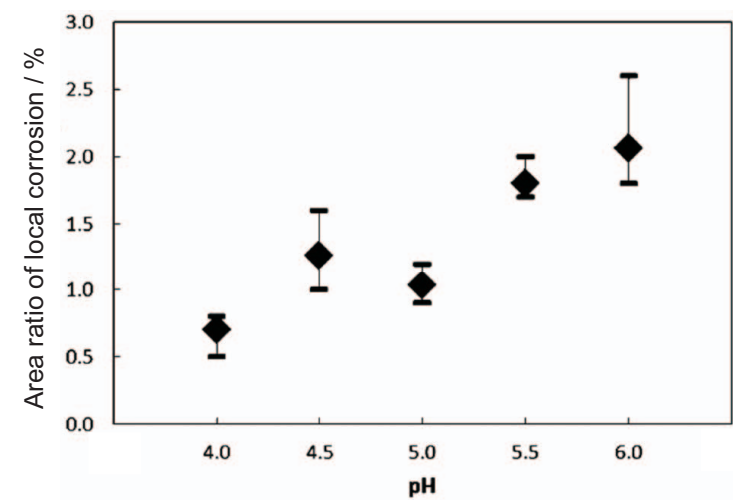

Fig. 6 Area ratio of local corrosion in different $\mathrm{pH}$.
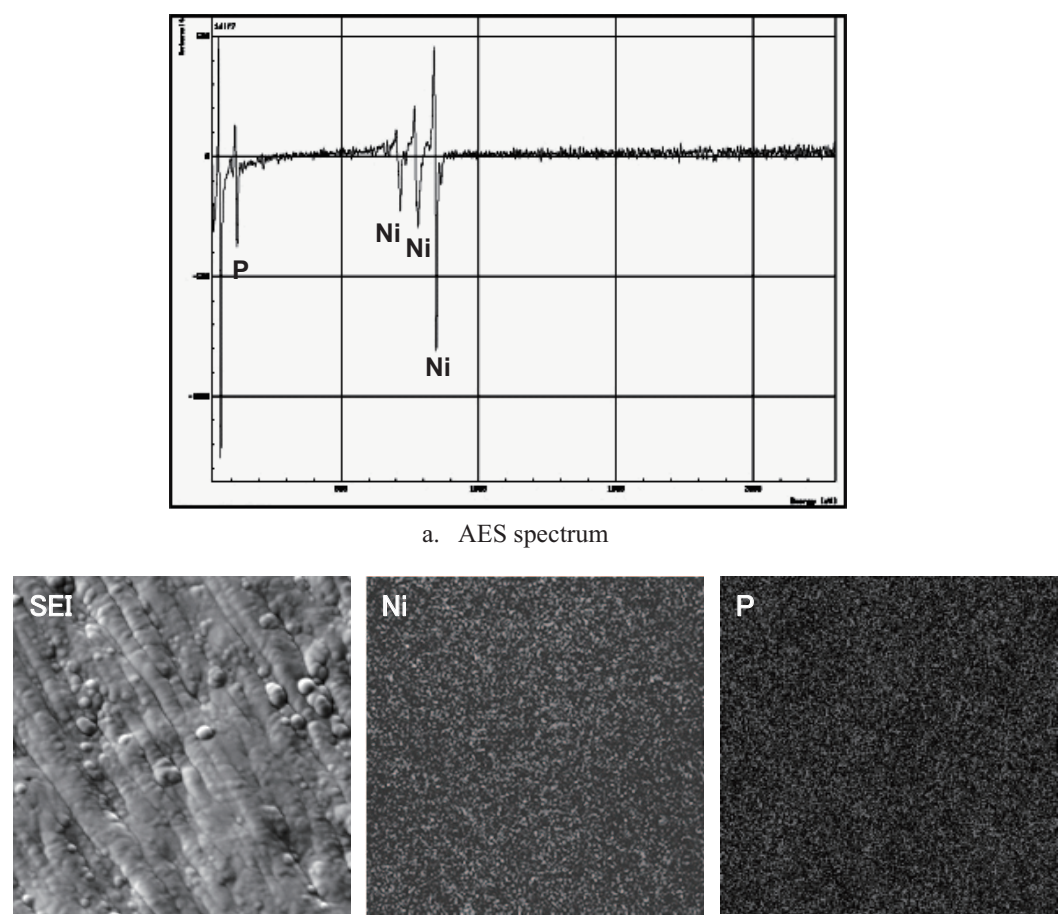

b. AES mapping

Fig. 7 AES analyses of Ni surface.

tion which may be a cause of local corrosion at the nodule boundaries. AES analyses were carried out after argon ion etching for $60 \mathrm{~s}$ to remove surface contamination on the nickel surface. An AES spectrum of the sample plated at pH 6.0 is shown in Fig. 7(a). No element except Ni and P is detected from the nickel surface. A SEM image and AES mappings are shown in Fig. 7(b). Distribution of $\mathrm{Ni}$ and $\mathrm{P}$ is very uniform, and there is no segregation which may be a cause of local corrosion. Meanwhile the sample plated at pH 4.0 was analyzed. No impurities and segregations could be seen as well. With respect to the structures and composition which were described in previous section, there was no major difference among the samples. While the difference of phosphorous content had the potential to affect to local corrosion behavior, they were kept within middle phosphorous range. From these results of surface observations and elemental analyses, it is assumed that tensile internal stress in the nickel plating layer which generated depending on plating bath $\mathrm{pH}$ was highly-influential on local corrosion behavior rather than metallic structure or chemical composition.

\subsection{Solder ball shear test}

Fracture loads of solder ball shear test were plotted as a function of plating bath $\mathrm{pH}$ in Fig. 8. The specimens plated at $\mathrm{pH} 4.0$ which had compressive stress showed stable fracture load over $20 \mathrm{~N}$. While an average of the fracture loads of specimens plated at $\mathrm{pH} 5.0$ was approximately equivalent to that of $\mathrm{pH} 4.0$, lower variability became wider than $\mathrm{pH}$ 4.0. Joining strength deteriorated to $15 \mathrm{~N}$ in average in case of $\mathrm{pH} 6.0$ which had tensile stress. Since the 
internal stress and the local corrosions at the surface of the nickel layer depending on plating bath $\mathrm{pH}$ would have potential to affect to solder ball joining strength, relativity between these behaviors and joining strength was considered through observation of fracture surfaces and crosssections of joining interfaces. Figure 9 indicates the fracture surfaces of solder ball shear test and the cross-sections before and after ball shear tests. In case of the specimen plated at $\mathrm{pH} 4.0$, the whole fracture surface presented metallic ductile fracture behavior. And since no defects could be seen at the interface between solder and nickel, it was confirmed the fracture occurred inside the solder. Combination of ductile fracture and dimple shaped surface were seen in the specimens plated at $\mathrm{pH}$ 5.0. The fracture occurred inside the solder, but partially it propagated at the nickel surface. As shown in cross-sectioned image, there were some solder voids adjacent to the join-

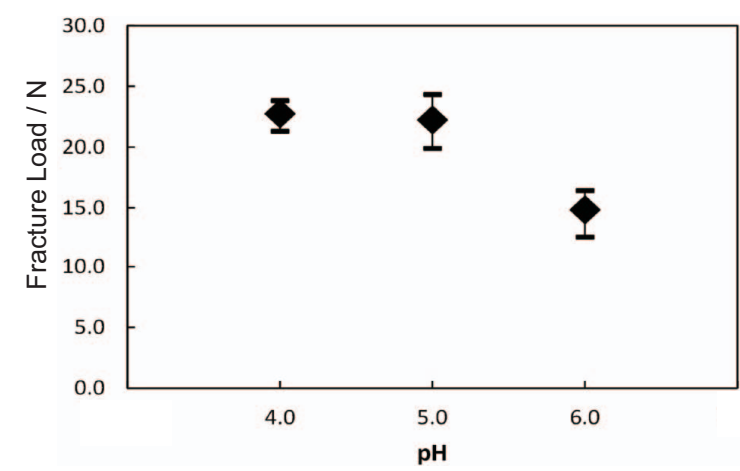

Fig. 8 Shear test results. ing interface. They seemed to correspond to fracture propagation at the joining interface and the dimple shaped fracture surface. In case of the specimens plated at $\mathrm{pH}$ 6.0, all of them presented dimple shaped fracture surface. As indicated in Fig. 9.3.c, numerous voids existed adjacent to the joining interface. Since shear strengths seemed to decrease as increasing dimples in the fracture surfaces, it was assumed that existence of the solder voids would be a cause of joining strength deterioration.

The cross-sectioned joining interfaces were analyzed in high magnification using FE-SEM and EDS in order to consider the cause of solder voids. As shown in Fig. 10, local corrosion defects could be seen at the surface of the nickel plating layer, and circular shaped voids were present in the solder corresponding to the location of the local corrosions. The local corrosion defects were hollowness, and some white colored particles could be seen on the inner wall of the defects. From the results of EDS analyses, Au was detected from the white particles (Fig. 11.b). By ordinary, gold plated layer which deposited on the nickel surface dissolves immediately in the molten solder. Thus the existence of remaining Au indicates that molten solder did not contact the surface of the inner wall of the defects. The gold particles seemed to be agglomerated depositions. This indicated that nickel surface of the inner wall was revealed without gold. Hence it was presumed that molten solder did not wet the inside of the local corrosion defects due to the oxidation of the nickel surface. This
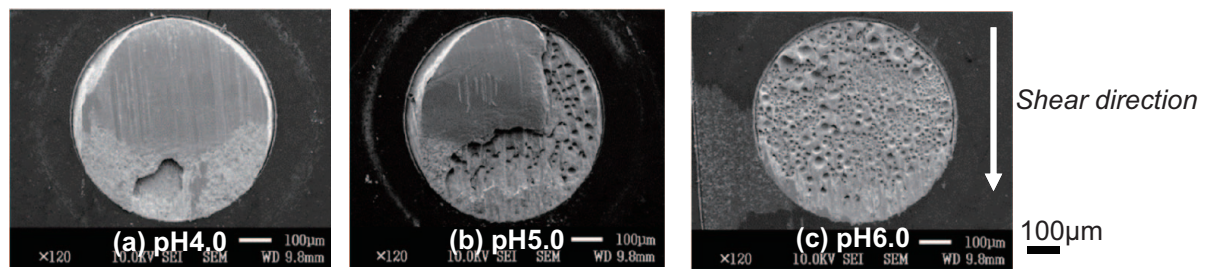

1. Fracture surfaces
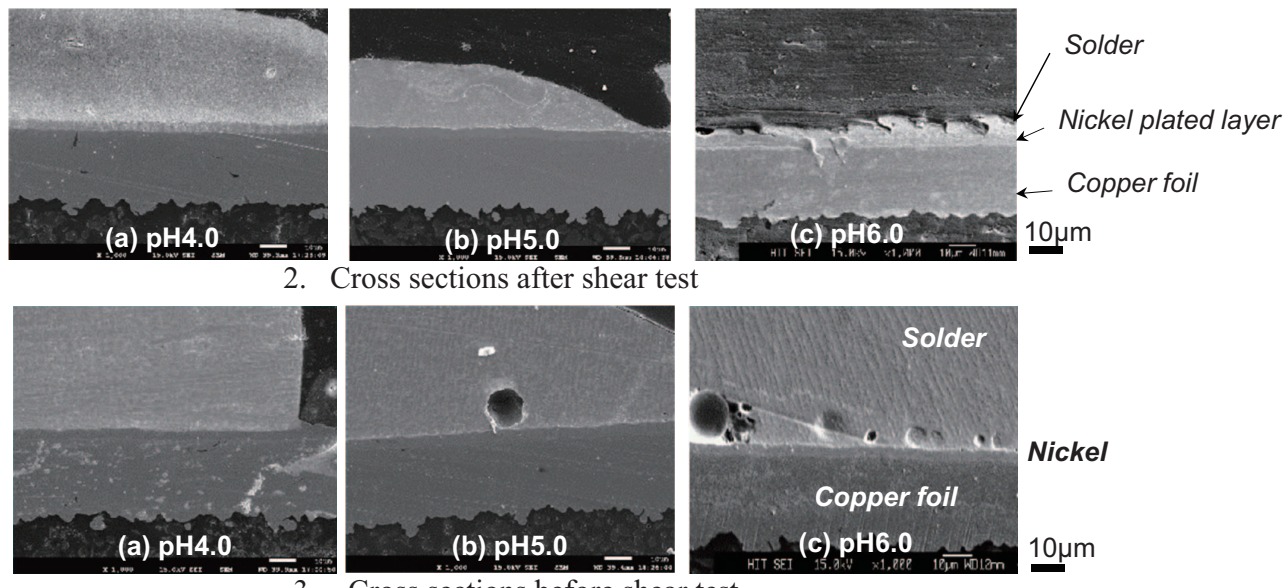

3. Cross sections before shear test

Fig. 9 Fracture surfaces and cross sections. 

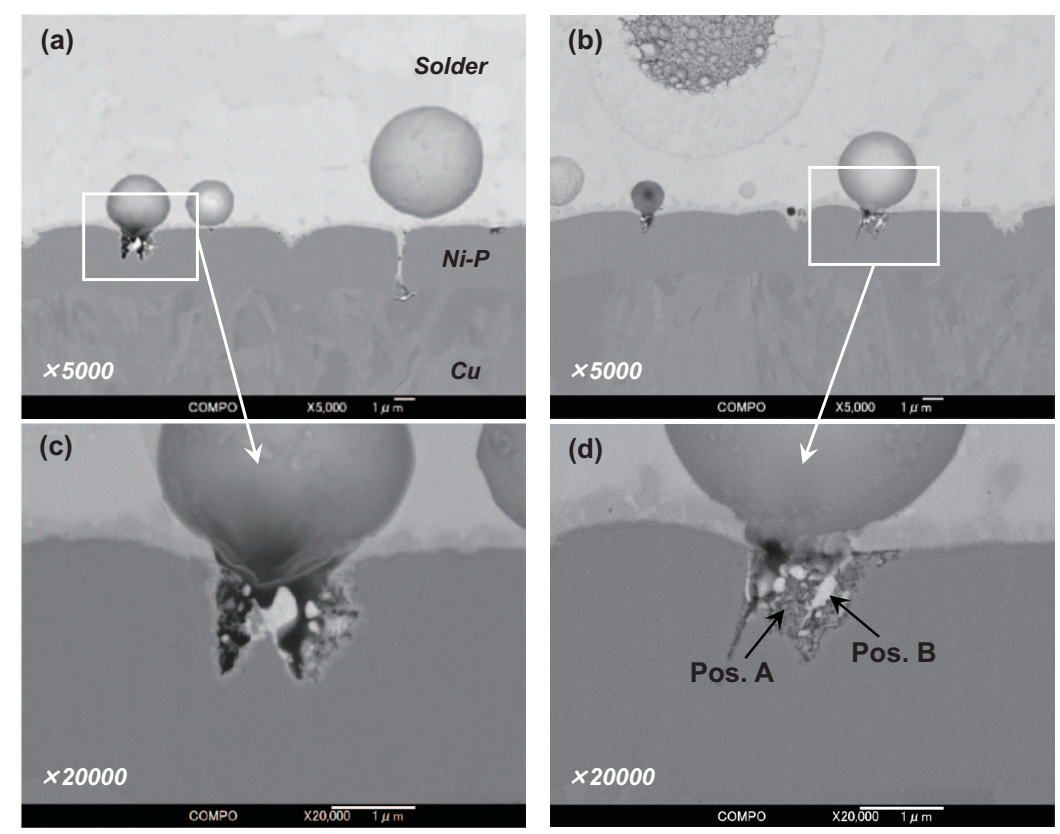

Fig. 10 Fine observation of solder voids and local corrosion defects.
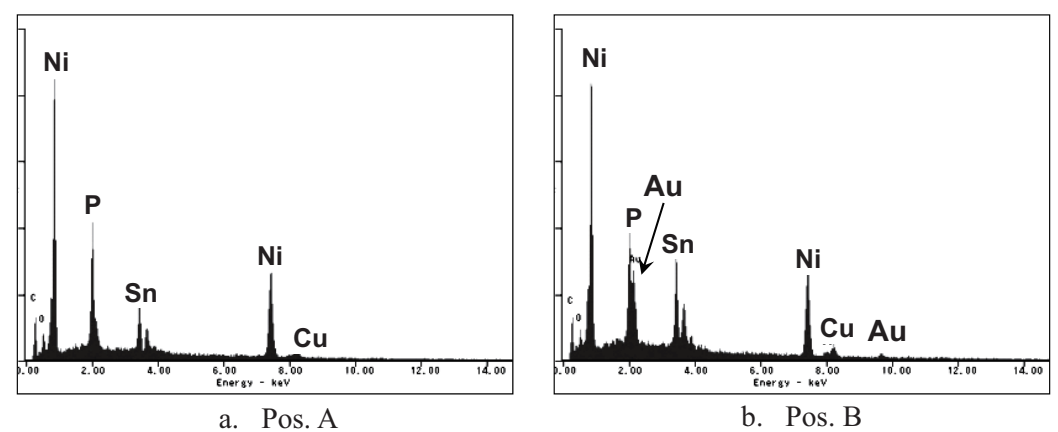

Fig. 11 EDS analyses inside the local corrosion defects.

caused the solder voids adjacent to the joining interface and resulted in deteriorate of solder joining strength.

\section{Conclusion}

Effects of internal stress of electoless nickel plating on behavior of local corrosion and solder joining strengths were evaluated varying $\mathrm{pH}$ of nickel plating bath. Local corrosion defects increased depending on raising $\mathrm{pH}$ due to increasing tensional internal stress of nickel layer. Beyond, solder ball shear strength was deteriorated as raising $\mathrm{pH}$ of plaiting bath. The solder voids adjacent to the joining interface between solder and nickel increased depending on raising $\mathrm{pH}$ which makes internal strength tensional. It was assumed that local corrosion defects at nickel surface would be a cause of solder voids.

To summarize, it became clear that internal stress of nickel plating layer affected to local corrosion behavior. While compressive internal stress brings few local corrosion defects and excellent solder joining strength, tensile internal stress results in deterioration of solder joining strength due to the solder voids at the joining interface.

\section{Acknowledgment}

FIB cross-sectioning and AES analyses in this study were carried out supporting by The Nanotechnology Platform at Hokkaido University. We would like to express our special thanks to them.

\section{References}

[1] K. Tajima, "ENEPIG as Final Finish Plation on Printed Wiring Board and Package Substrate,” J. Surf. Finish. Soc. Jpn, Vol. 62, No. 8, pp. 387-391, 2011.

[2] Y. Ejiri, T. Sakurai, Y. Arayama, K. Suzuki, Y. Tsubomatsu, S. Hatakeyama, et al., "Electroless Ni/ $\mathrm{Pd} / \mathrm{Au}$ Plating for Semiconductor Package Substrates (I) - Influence of the Electroless Ni Plating Thickness on the Solder Ball Joining Reliability -,” The Journal of The Japan Institute of Electronics Packaging, Vol. 
15, No. 1, pp. 82-95, 2012.

[3] K. Iwamatsu and K. Otsuka, "The internal stress of Electroless Deposits,” K. Naito, J. Surf. Finish. Soc. Jpn, Vol. 43, No. 7, pp. 656-666, 1992.

[4] B. Stein, "Fast and Accurate Deposit Internal Stress Determinartion,” Proc. AESF Electroforming Symposium, 1996.

[5] G. Richardson and B. Stein, "Comparative Study of
Three Internal Stress Measurement Methods," AESF Electroforming Symposium, 1997.

[6] G. G. Stoney, "The Tension of Metallic Films deposited by Electolysis," Proceedings of Royal Society, A82, 172, 1909.

[7] K. Oyamada and W. Yamamoto, "Measurements of Internal Stresses in Electrodeposits,” J. Surf. Finish. Soc. Jpn, Vol. 58, No. 4, pp. 213-218, 2007.
Katsumi Miyama is professor at the Mechanical Engineering Department at the Hokkaido University of Science, Japan. He was licensed as a professional engineer (PE.jp) in 1998 and received Ph.D degree from Hokkaido Institute of Technology in 2013. Katsumi Miyama is vice chair of the Device Embedding Technology Committee, established by JIEP. He has been working on device embedded substrates and high density wiring of Printed Wiring Board throughout his working career in companies and university.

Kanou Yoshida is assistant professor at the Mechanical Engineering Department at the Hokkaido University of Science. He received B.E. degree from the Hokkaido Institute of Technology in 1986. Kanou Yoshida has been working on studies of behavior of cutting parameters in metal cutting process.
Shigeru Saitou is associate professor at the Mechanical Engineering Department at the Hokkaido University of Science. He received Ph.D degree from the Hokkaido University in 2008. Shigeru Saitou has been working on structural stability of diffusion barrier coating at high-temperatures based on experimental phase diagrams.

Toshiyuki Takashima is vice president at the Hokkaido University of Science and professor at the Mechanical Engineering Department. He received Ph.D degree from the Hokkaido University in 1992. Toshiyuki Takashima has been working on studies of ceramic-to-metal-joining and surface treatment for long yeas. In 2014, he was awarded by The Japan Society of Corrosion Engineering for his contribution as the manager of Hokkaido branch. 